\title{
A CHAIN OF NUMERICAL RADIUS INEQUALITIES IN COMPLEX HILBERT SPACE
}

\author{
Mohammed Al-Dolat* , Ayat Dagher and Marwan Alquran
}

\begin{abstract}
In this paper, we implement the improvement of numerical radius inequalities that were produced by Alomari MW. [Refinements of some numerical radius inequalities for Hilbert space operators. Linear and Multilinear Algebra. 2019 Jun 4:1-6] and devise a new upper bound for $2 \times 2$ operator matrices on complex Hilbert space with many examples which show that our bound is sharper than the existing bounds proved by Bani-Domi W, Kittaneh F. [Norm and numerical radius inequalities for Hilbert space operators. Linear and Multilinear Algebra. 2020 Jul 28:1-2], Al-Dolat M, Jaradat I, Al-Husban B. A novel numerical radius upper bounds for $2 \times$ 2 operator matrices. Linear and Multilinear Algebra. 2020 Apr 23:1-2], Shebrawi K. [Numerical radius inequalities for certain $2 \times 2$ operator matrices II. Linear Algebra and its Applications. 2017 Jun 15; 523:1-2] and Hirzallah O, Kittaneh F, Shebrawi K. [Numerical radius inequalities for $2 \times 2$ operator matrices. Studia Mathematica. 2012; 210:99-115].
\end{abstract}

Mathematics subject classification (2020): 47A12, 47A30, 47A63, 47B33.

Keywords and phrases: Numerical radius, spectral radius, operator matrix.

\section{REFERENCES}

[1] F. Kittaneh Y. ManasRah, Improved Young and Heinz inequalities for matrices, J. Math. Appl. 361 (2010) 262-269.

[2] F. KitTANEH, A numerical radius inequality and an estimate for the numerical radius of the Frobenius companion matrix, Studia Math. 158 (2003) 11-17.

[3] M. AlomRI, Refinement of some numerical radius inequalities for Hilbert space operators, Linear Multilinear A. (2019), https://doi.org/10.1080/03081087.2019.1624682.

[4] Y. Manasrah, F. Kittaneh, A generalization of two refined Young inequalities, Positivity 19 (2015) 757-768.

[5] D. CHOI, A generalization of Younge-type inequalities, Math. Inequal. Appl. 21 (2018) 99-106.

[6] F. KitTaneH, Spectral radius inequalities for Hilbert space operators, Proc. Am. Math. Soc. 134 (2) (2005) 385-390.

[7] F. Kittaneh, Notes on some inequalities for Hilbert space operators, Publ. Res. I. Math. Sci. 24 (1988) 283-293.

[8] K. SheBRAwI, Numerical radius inequalities for certain $2 \times 2$ operator matrices II, Linear Algebra Appl. 523 (2017) 1-12.

[9] S. S. Dragomir, Some refinements of Schwarz inequality, Simposional de Math Si Appl. Polytechnical Inst Timisoara, Romania, 1-2, (1985) 13-16.

[10] M. Sattari, M. S. Moslehian, T. YAmAZAKI, Some generalized numerical radius inequalities of Hilbert space operators, Linear Algebr Appl. 470 (2015) 216-227.

[11] T. YAMAZAKI, On upper and lower bounds of the numerical radius and an equality coditions, Studia mathematica 178 (2007) 83-89.

[12] R. BAhtia, Matrix analysis, volume of Graduate texts in mathematics, 1997.

[13] O. Hirzallah, F. Kittaneh, K. Shebrawi, Numerical radius inequality for certain $2 \times 2$ operator matrices, Integral Equations Operator Theory 71 (1997) 129-149.

[14] O. Hirzallah, F. Kittaneh, K. Shebrawi, Numerical radius inequalities for $2 \times 2$ operator matrices, Studia Mathematica 15 (2012) 99-115. 
[15] W. BANI-Domi, F. KitTANEH, Norm and numerical radius inequalities for Hilbert space operators, Linear and Multilinear Algebra (2020), https://doi.org/10.1080/03081087.2020.1798334.

[16] M. Al-Dolat, I. Jaradat, I. Al-Husban, Anovel numerical radius upper bound for $2 \times 2$ operator matrices, Linear and Multilinear Algebra (2020), https://doi.org/10.1080/03081087.2020.1756199. 